\title{
THE CLIMBING PREFERENCES OF ADVANCED ROCK CLIMBERS
}

doi: 10.2478/humo-2013-0031

\section{ARTUR MAGIERA*, ROBERT ROCZNIOK}

The Jerzy Kukuczka Academy of Physical Education, Katowice, Poland

\begin{abstract}
Purpose. Previous studies have broadened the knowledge about the general characteristics of rock climbing. However, there is a lack of research on rock climbers who are at a similar performance level but have different climbing preferences. The purpose of this study was to focus on what similarities and differences are present in the anthropometric, physiological, and training characteristics of advanced rock climbers. Methods. A group of 31 advanced Polish rock climbers volunteered to participate in the study. A questionnaire was administered to determine their climbing preferences. The participants' anthropometric characteristics, physical fitness, and aerobic power were measured using standard methods. Results. Similarities were found among the climbers in terms of the training exercises they used, their preference for certain types of rock faces and rock handholds, and their participation in different types of climbing and other sports disciplines. Differences were found among various anthropometrical characteristics, physical fitness, and training exercise frequency between climbers who preferred different climbing styles (on-sight vs. redpoint) or climbing routes (“crux" vs. “endurance”). Conclusions. During the off-season, various training exercises were used, with the majority employing specialized forms of training (bouldering, repeating previously climbed routes, and leading routes in different styles). They practised on average 10 hours a week and preferred climbing overhanging walls with edge handholds. The best results the climbers achieved in on-sight climbing were in foreign countries and by individuals with high aerobic power measured by an arm ergometer test. Climbers who achieved better results in redpointing used the Campus board more frequently when training and completed their most difficult climbs in Poland. Additional differences were noted between climbers who preferred endurance routes and those who preferred shorter climbing efforts (crux routes), with the former presenting better finger flexor muscle endurance and greater muscle mass.
\end{abstract}

Key words: rock climbing, preferences, training

\section{Introduction}

Rock climbing is a very diverse form of physical activity. It can be differentiated by numerous criteria such as the length and endurance of a climb (from completing one short, intensive bouldering problem to a multi-day, oxygen-deficient Himalayan climb), the type of risk involved (from free soloing on mountain peaks to secured climbs on artificial rock walls), or the amount of tools and equipment required (from only a pair of shoes and a chalk bag to several dozen kilograms of equipment on a multi-day aid climb). The extensive variety of climbing subtypes makes the sport attractive to a wide range of individuals. Even narrowing the above considerations and naming them as one sub-discipline of mountaineering - rock climbing - still leaves climbers with numerous choices (e.g., climbing style, length, type of rock face) that can be matched to their own personal preferences, talents, and strengths (in terms of skill, ability, body build, psychological readiness, etc.).

Among the various climbing preferences individuals may have, there also exist those that relate to the type of actions they prefer to perform over others when training or during the climbing season. Individual preferences are

\footnotetext{
* Corresponding author.
}

subject to contextual personality- and environmentallybased factors that create a system of assessments and priorities to which one thing or activity is valued over another, creating, in effect, a hierarchical scale [1]. They are fundamental in nature and specify the original basis for a person interested in a specific activity. As a result, there exist large inter-individual variations among athletes in the sporting environment. This principle is reflected in sports training by the need to include all the features and characteristics an athlete possesses, while taking into consideration their individual strengths and ability to improve during the training process [2].

The amount of research conducted on rock climbing has been steadily increasing over recent years. The majority of studies have focused on the energy requirements [3-8], anthropometric characteristics, or fitness levels of climbers [9-11]. Some have sought to understand the determinants of sporting success in rock climbing competitions $[12,13]$. These studies have increased knowledge on rock climbing per se in terms of its physical demands and the characteristics of its participants. However, there is still a lack of information on the types of climbers that exist, such as differences in climbers at a similar skill level in respect to their preference for one aspect of climbing over another. This study aimed to bridge this gap by focusing on the similarities and differences in advanced climbers in terms of their morpho- 
functional traits and training characteristics. The study sought to answer the following questions:

1. What are the characteristics of advanced rock climbers in terms of:

a) the training exercises they perform during the off-season,

b) the rock faces and rock holds they prefer to climb, and

c) their involvement in other types of climbing or sports disciplines?

2. Are there any anthropometric and physical fitness characteristics that determine a climber's preference for a particular climbing style $\left(\mathrm{OS}^{1}\right.$ or $\left.\mathrm{RP}^{2}\right)$ ? Additionally, are there any differences in the training exercises used by climbers who prefer OS or RP?

3. Which anthropometric and fitness characteristics as well as training exercises differentiate climbers who prefer short $(<15 \mathrm{~m})$ climbing routes or with only one difficult move to those who prefer endurance-based climbs?

\section{Material and methods}

Thirty-one advanced rock climbers from Poland were recruited to participate in the study. The minimum size of the sample ${ }^{3}$ was determined by statistical means. Inclusion criteria when selecting the sample population among advanced Polish climbers were being at least 18 years of age and having on-sighted a route graded at least VI.2, based on the Polish (Kurtyka) scale. Their highest mean graded on-sight climb was VI.4/4+ (VI.2-VI.5+) and VI.5+ (VI.4-VI.7) when redpointing. All were male, with a mean age of $26.74 \pm 5.43$ years and $8.32 \pm 3.43$ years' experience in rock climbing. All provided their written informed consent to participate in the study. The study was conducted in 2004.

Data on the participants were collected by use of a diagnostic survey to determine their climbing preferences and direct observation to measure their anthropometric characteristics and fitness levels. The questionnaire asked the participants about:

- what kinds of the training exercises (TE) they used when training during the off-season, separated as either general training exercises $(\mathrm{G})$, targeted training exercises $(\mathrm{T})$, or specialized training exercises (S):

\footnotetext{
${ }^{1}$ OS (on-sight) - a lead climbing style performed without falling and without aid or foreknowledge of the route.

${ }^{2} \mathrm{RP}$ (redpoint, based on the German 'Rotpunkt') - a freeclimbing style performed without falling in one go without rest, although with prior knowledge of the route after having practiced it beforehand.

${ }^{3}$ The number of advanced rock climbers in Poland who participated in the 2004 Polish Cup was 48 (www.pza.org), with the estimated number of climbers who had completed an on-sight VI. 2 graded climb or higher in Poland to be about 400 (source: own data).
}

- general training consisted of: standard warmup exercises (TE G1), resistance training using machines or free weights (TE G2), stretching exercises (TE G3), relaxation exercises (TE G4), coordination exercises (TE G5), running (TE G6), swimming (TE G7), and playing any other team or individual sport (TE G8);

- targeted training: pull-up bar exercises including pull-ups, chin-ups, lock-offs (TE T1), Bachar ladder (a rope ladder) exercises (TE T2), dynamic climbing exercises performed without the use of the legs on a Campus board, a board with slates of wood attached in a ladder-like configuration (TE T3), finger board training by hanging and climbing on various poles (TE T4), exercises performed on a system wall, a small climbing wall used to repeat climbing movements (TE T5), mixed static-dynamic arm exercises performed on a peg board using only the arms (TE T6), exercises performed using a gymnastic wall bar (TE T7), and other types of exercises similar to the ones above (TE T8);

- specialized training: bouldering problems consisting of a few although very intensive climbing movements (SE S1), circuit bouldering exercises performed at low height without the use of a safety rope (SE S2), exercises targeted to practice leading in the on-sight, flash, or redpoint styles of climbing while using a safety rope (SE S3), technique exercises (SE S4), tactics training such as how to plan new routes, how to find resting spots, where to attach the rope to the quickdraw, or how to direct a partner where the best handholds are when bouldering (SE S5), repeating well-known routes for practice (SE S6), and any other specialized forms of training (SE S7);

- the frequency of using the above exercises, the amount of time they spent training per week (Training), the average time spent rock climbing outdoors during the season (Outdoors), and the number of years of climbing experience (Exp.);

- their preferred types of rock faces (Faces) and rock handholds (Handholds);

- their preferred type of climbing route:

- routes with only one difficult move or a short $(<15 \mathrm{~m})$ route performed at a constant, submaximal intensity (“Crux" routes),

- long $(>15 \mathrm{~m})$ routes performed at an intermittent or constant but high intensity ("Endurance" routes);

- their highest graded on-sight (OSmax) and redpoint (RPmax) climb rated on a decimal scale [14], as the currently used grading scales are difficult to subject to statistical analysis; and

- how many types of climbing they participate in (Climb. types). 
A. Magiera, R. Roczniok, The climbing preferences of advanced rock climbers

The reason for the methodological division of the participants' training exercises as general, targeted, and specialized was the specificity of each training exercise in regards to their in-season performance (i.e., attempting the climb their most difficult route - OSmax and RPmax). Hence, the reason why exercises aimed at improving overall fitness and not only those specifically connected with rock climbing were included in the general training group. Targeted training was considered to be exercises performed on devices that can improve climbing skills by engaging those muscles most involved in climbing. This category included exercises that improve overall physical fitness but have little impact on climbing technique or tactics or the climber's psyche. The last category (specialized training) included all training exercises that required practicing different kinds of climbing handholds involving a high degree of climbing technique and tactics.

The climber's anthropometric characteristics were measured using methods widely adopted in sports anthropology. Body composition was assessed by bioelectrical impedance using a BIA-101/SC analyzer (Akern, Italy) and the packaged Bodygram software. The participants were measured for body mass (Mass), body height (Height), Ape Index (the ratio of arm length to body height [13]), percent body fat (BF\%), percent muscle mass (MM\%), and Body Mass Index (BMI). In addition, the flexibility of the climbers was also assessed by measuring the range of movement of the lower limbs at the hips by use of a goniometer [16]: this included measures of flexion (Flex.) and abduction (Abduc.) as well as hip flexibility in the "frog" (Frog) position (measured as the distance from the pubic symphysis to the wall when sitting feet placed together with the legs spread as far as possible to the sides).

The participants' fitness included measures of: finger strength (FSmax - the isometric strength of four outstretched fingers on a dynamometer [17]), shoulder muscle strength (SMSmax - performing one weighted pull-up with maximum load, 1RM), endurance of Type I flexor finger muscles (FFMmax50\% - maintaining grip with four fingers at $50 \%$ FSmax during a continuous isometric contraction), endurance of Type II flexor finger muscles (FFMmax70\% - maintaining grip with four fingers at 70\% FSmax until exhaustion during an isometric contraction performed for $10 \mathrm{~s}$ under load followed by 10 s of rest [18]), and shoulder static muscular endurance (SSME - time of bent-hang hang until exhaustion).

Aerobic capacity was measured in laboratory conditions on an E-824 ergometer (Monark, Sweden) that was modified for arm crank ergometry. The test began with a load of $15 \mathrm{~W}$, with resistance gradually increased adding $15 \mathrm{~W}$ every 2 min and performed until exhaustion. Ergospirometry variables measured during the test included maximal oxygen consumption $\left(\mathrm{VO}_{2} \mathrm{max}\right)$ and oxygen uptake at the anaerobic threshold $\left(\mathrm{VO}_{2} \mathrm{AT}\right)$.

Statistical analysis consisted of calculating basic descriptive statistics (arithmetic mean, standard deviation, median, maximum and minimum values, and variability). The Mann-Whitney $U$ test was used to determine the level of significance. The results were also analyzed with the $\chi^{2}$ test and multivariate cluster analysis. Cluster analysis is a useful method for grouping a large number of variables in several subsets (clusters) that relate to one another by use of a dendrogram. The collected data were first standardized by specifying for each value a coefficient calculated from the mean value and standard deviation. The dendrogram was then created based on Ward's method of hierarchical clustering, which minimizes the sum of the squared deviations of any two clusters that can be formed at any stage. As the original values were continuous variables, the Euclidean distance was adopted to measure the similarities of the clusters by the formula: $(\mathrm{x}, \mathrm{y})=\left\{\Sigma_{\mathrm{i}}\left(\mathrm{x}_{\mathrm{i}}-\mathrm{y}_{\mathrm{i}}\right)^{2}\right\}^{1 / 2}$.

\section{Results}

Table 1 presents the anthropometric characteristics and fitness levels (flexibility, muscular strength, and aerobic capacity during the arm ergometer test) of the rock climbers including their climbing experience and training history.

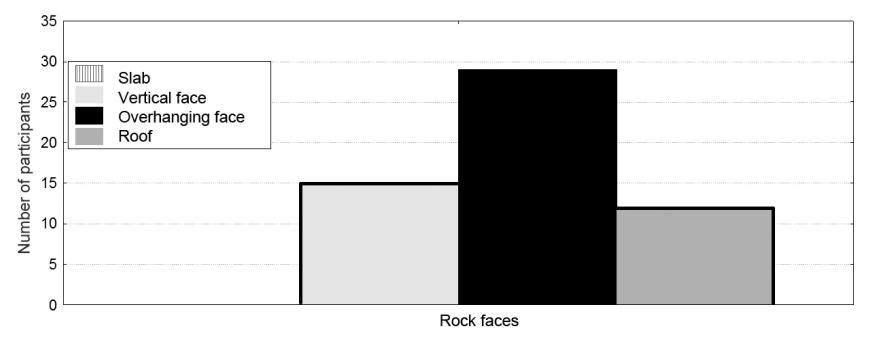

Figure 1. Advanced rock climbers' preferences for certain rock faces

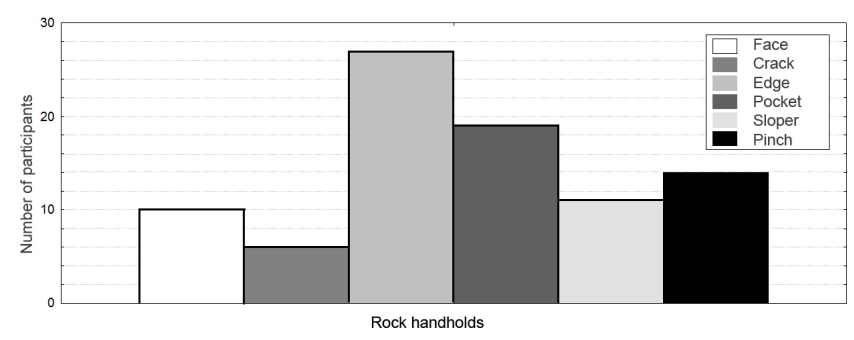

Figure 2. Advanced rock climbers' preferences for certain rock handholds

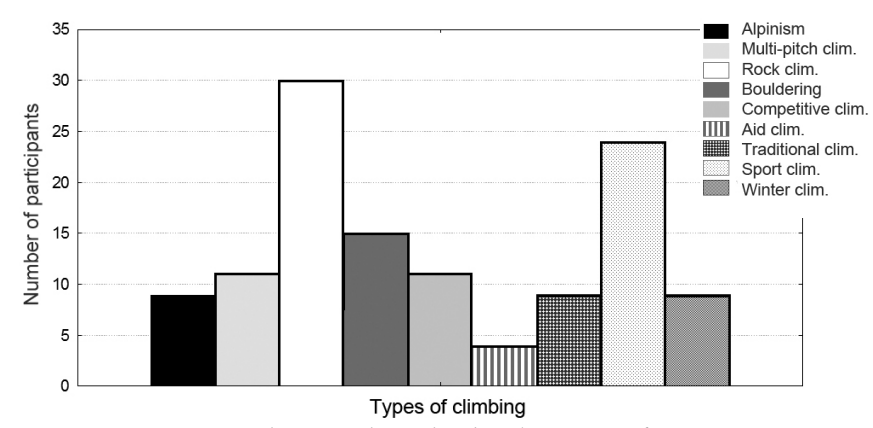

Figure 3. Advanced rock climbers' preferences for climbing subtypes 
Table 1. Anthropometric, climbing, and physical fitness characteristics of advanced rock climbers

\begin{tabular}{|c|c|c|c|c|c|c|c|}
\hline Variable & Abbreviation & Unit & Mean & $S D$ & Min & Max & Variability \\
\hline Highest graded on-sight climb & OSmax & $\mathrm{n}$ & 8.63 & 0.57 & 7.35 & 9.50 & 6.60 \\
\hline Highest graded redpoint climb & RPmax & $n$ & 9.52 & 0.58 & 8.50 & 10.40 & 6.09 \\
\hline Climbing experience & Exp. & years & 8.32 & 3.43 & 2.00 & 16.00 & 41.23 \\
\hline Training frequency & Training & h/week & 10.08 & 3.61 & 4.50 & 16.00 & 35.81 \\
\hline Age & Age & years & 26.74 & 5.43 & 18.00 & 38.00 & 20.31 \\
\hline Climbing subtypes & Climb. types & $n$ & 3.97 & 2.24 & 1.00 & 9.00 & 56.42 \\
\hline Outdoor climbing frequency & Outdoors & $n /$ week & 2.95 & 0.99 & 0.50 & 4.50 & 33.56 \\
\hline Body mass & Mass & $\mathrm{kg}$ & 68.60 & 5.17 & 54.30 & 78.50 & 7.54 \\
\hline Body height & Height & $\mathrm{cm}$ & 177.78 & 5.58 & 167.00 & 187.70 & 3.14 \\
\hline Ape index & Ape index & $\mathrm{cm} / \mathrm{cm}$ & 1.01 & 0.02 & 0.97 & 1.07 & 1.98 \\
\hline Percent body fat & $\mathrm{BF} \%$ & $\%$ & 10.40 & 3.25 & 4.60 & 17.90 & 31.25 \\
\hline Percent muscle mass & MM\% & $\%$ & 63.73 & 8.23 & 45.30 & 84.80 & 12.91 \\
\hline Body Mass Index & BMI & $\mathrm{kg} / \mathrm{m}^{2}$ & 21.76 & 1.71 & 18.00 & 25.50 & 7.86 \\
\hline Flexion at the hip & Flex. & degrees & 119.32 & 10.52 & 105.00 & 139.00 & 8.82 \\
\hline Abduction at the hip & Abduc. & degrees & 51.10 & 6.98 & 35.00 & 67.00 & 13.66 \\
\hline Hip flexibility in the "frog" position & Frog & $\mathrm{cm}$ & 6.05 & 5.07 & -3.00 & 17.20 & 83.80 \\
\hline Finger strength & FSmax & $\mathrm{kg} / \mathrm{kg}$ & 0.56 & 0.06 & 0.42 & 0.69 & 10.71 \\
\hline Finger endurance - Type I & FFMmax $50 \%$ & s & 94.61 & 24.64 & 63.00 & 192.00 & 26.04 \\
\hline Finger endurance - Type II & FFMmax70\% & $\mathrm{s}$ & 354.00 & 198.81 & 130.00 & 900.00 & 56.16 \\
\hline Shoulder muscle strength & SMSmax & $\mathrm{kg} / \mathrm{kg}$ & 1.64 & 0.12 & 1.43 & 1.88 & 7.32 \\
\hline Shoulder muscle endurance & SSME & s & 67.19 & 13.63 & 44.00 & 90.00 & 20.29 \\
\hline Aerobic capacity during arm test & $\mathrm{VO}_{2} \max$ & $\mathrm{ml} / \mathrm{kg} / \mathrm{min}$ & 36.05 & 6.76 & 20.50 & 49.40 & 18.75 \\
\hline Anaerobic threshold during arm test & $\mathrm{VO}_{2} \mathrm{AT}$ & $\mathrm{ml} / \mathrm{kg} / \mathrm{min}$ & 24.32 & 5.48 & 13.07 & 35.05 & 22.53 \\
\hline
\end{tabular}

In terms of the participants' climbing preferences, the majority (94\%) preferred climbing overhang faces (Fig. 1). None of the climbers (0\%) preferred climbing on rock faces angled less than 90 degrees (slab faces). The edge (85\%) and pocket (61\%) rock handholds were rated higher over the others (Fig. 2). Only 19\% of the participants liked to climb on rock faces that had longitudinal cracks in the rock.

The climbing sub-disciplines the participants were involved in are presented in Figure 3. Although the climbers in the present study were very experienced, none specialized in only one type of climbing. The majority practiced at least three climbing subtypes (median $=3$ types, mean $=3.97 \pm 2.24$, Tab. 1 ), with the most popular being rock climbing (97\%), climbing on bolted climbing routes (77\%), and bouldering (48\%). Only $36 \%$ of the climbers competed in climbing competitions, mainly in bouldering (73\% of those competing) and lead climbing $(46 \%)$. Only one person in the study competed in speed climbing.

The training exercises used by the climbers during the off-season are presented in Table 2 (rated on a fivepoint scale, where "1" denotes never using this type of exercise to " 5 ", where it was almost always used in every training session). As none of the participants performed exercises TE T6, TE T8, and TE S7, they were excluded in subsequent analysis. Among the "Other sports" category (TE G8) the participants performed as a general training exercise, six climbers reported that they prac- ticed cycling, five climbers participated in winter sports, two climbers were involved in team sports, and several individuals practiced gymnastics, boxing, or yoga.

Cluster analysis was performed in order to group the above data and compare what exercises were used more commonly with others (Fig. 4). The resulting dendrogram split the types of training exercises into three clusters at a Euclidean distance of 15:

- almost always or often performed included warmup exercises, bouldering exercises (problems and circuits), pull-up exercises, repeating climbing routes, Campus board training, and training leading in the OS, FL, and RP styles;

- exercises sometimes performed included stretching and relaxation exercises, tactics training, running, and other sports; and

- exercises performed rarely or never included resistance training, swimming, finger board and system wall training, technique practice, coordination exercises, and Bachar ladder training.

An indirect assessment of climbing preferences in terms of style (on-sight or redpoint)

Mastering difficult climbs (sporting success) for many advanced climbers was found to be a priority and not a side interest. Most of the climbers in the present study were found to achieve proportionately high results in completing routes both with (on-sight) and without 
A. Magiera, R. Roczniok, The climbing preferences of advanced rock climbers

Table 2. Training exercises used by rock climbers during the off-season

\begin{tabular}{|c|c|c|c|c|c|c|c|}
\hline Exercise & Abbreviation & Mean & $S D$ & Median & Minimum & Maximum & Variability \\
\hline \multicolumn{8}{|l|}{ General training exercises } \\
\hline Warm-up exercise & TE G1 & 4.68 & 0.65 & 5.00 & 2.00 & 5.00 & 13.89 \\
\hline Resistance training & TE G2 & 2.36 & 1.17 & 2.00 & 1.00 & 5.00 & 49.58 \\
\hline Stretching exercises & TE G3 & 3.39 & 1.20 & 3.00 & 1.00 & 5.00 & 35.40 \\
\hline Relaxation exercises & TE G4 & 2.74 & 1.34 & 3.00 & 1.00 & 5.00 & 48.91 \\
\hline Coordination exercises & TE G5 & 1.90 & 1.14 & 1.00 & 1.00 & 4.00 & 60.00 \\
\hline Running & TE G6 & 3.10 & 1.27 & 3.00 & 1.00 & 5.00 & 40.97 \\
\hline Swimming & TE G7 & 2.48 & 1.18 & 3.00 & 1.00 & 5.00 & 47.58 \\
\hline Other sports & TE G8 & 2.45 & 1.55 & 2.00 & 1.00 & 5.00 & 63.27 \\
\hline \multicolumn{8}{|l|}{ Targeted training exercises } \\
\hline Pull-up bar exercises & TE T1 & 3.52 & 0.85 & 4.00 & 2.00 & 5.00 & 24.15 \\
\hline Bachar ladder training & TE T1 & 2.29 & 1.32 & 2.00 & 1.00 & 5.00 & 57.64 \\
\hline Campus board training & TE T3 & 3.29 & 1.01 & 4.00 & 1.00 & 5.00 & 30.70 \\
\hline Finger board training & TE T4 & 2.32 & 1.19 & 2.00 & 1.00 & 5.00 & 51.29 \\
\hline System training & TE T5 & 2.13 & 1.36 & 2.00 & 1.00 & 5.00 & 63.85 \\
\hline Wall bar exercises & TE T7 & 1.71 & 1.04 & 1.00 & 1.00 & 5.00 & 60.82 \\
\hline \multicolumn{8}{|l|}{ Specialized training exercises } \\
\hline Bouldering problems & TE S1 & 4.23 & 0.88 & 4.00 & 2.00 & 5.00 & 20.80 \\
\hline Circuit bouldering & TE S2 & 4.10 & 0.83 & 4.00 & 2.00 & 5.00 & 20.24 \\
\hline Redpoint, flash, and on-sight leading & TE S3 & 3.45 & 1.41 & 4.00 & 1.00 & 5.00 & 40.87 \\
\hline Technique practice & TE S4 & 2.19 & 0.95 & 2.00 & 1.00 & 4.00 & 43.38 \\
\hline Tactics training & TE S5 & 3.03 & 1.17 & 3.00 & 1.00 & 5.00 & 38.61 \\
\hline Repeating climbing routes & TE S6 & 3.74 & 0.89 & 4.00 & 2.00 & 5.00 & 23.80 \\
\hline
\end{tabular}

Training frequency: 1 - never, 2 - rarely, 3 - sometimes, 4 - often, 5 - almost always

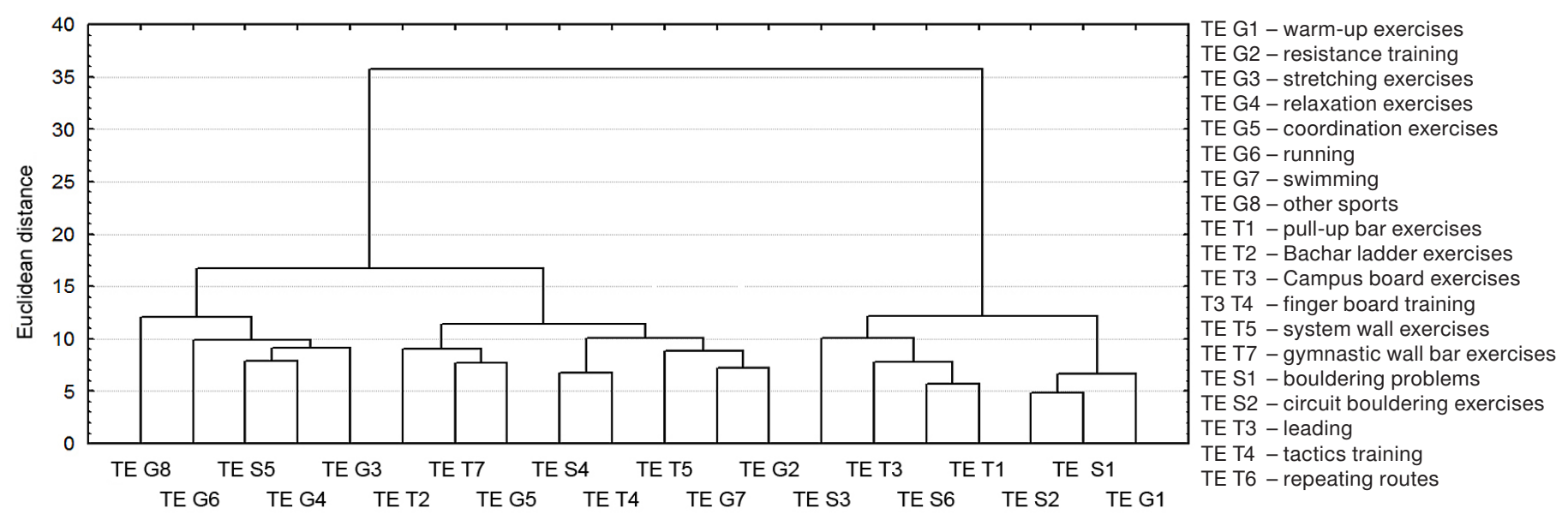

Figure 4. Frequency of training exercises (TE) during the off-season

(redpoint) foreknowledge, which points to their balanced development in climbing [19]. However, some of the climbers focused on only one of these styles, leading to their specialization and therefore achieving better results in either of the styles. The preference for one style over another can undoubtedly be related to what training exercises climbers' performed most often, the type of rock face they climb most often, and what technical difficulties they may expect to encounter.

This study used an indirect assessment of the climb- ers' preferred climbing style, which was based on their actions rather their own opinions. This method has certain drawbacks (the results not depending solely on the climbers' stated preferences), but does allow the defining of various morpho-functional and training factors differentiating the climbers who perform better in different climbing styles. In this case, determining the climbers' preferences was based on comparing their most accomplished climb (RPmax and OSmax). Due to the specificity of each style, there are differences in the 
Table 3. Results of the Mann-Whitney $U$ test for climbing style preference (OS vs. RP) in terms of the RP-OS index (only statistically significant characteristics are shown, $p<0.05$ )

\begin{tabular}{lccccc}
\hline Variable & Rank sum $(\mathrm{RP})$ & Rank sum $(\mathrm{OS})$ & $U$ & Corrected & $p$ level \\
\hline $\mathrm{VO}_{2} \max$ & 135.50 & 360.50 & 57.50 & -2.29 & 0.0219 \\
$\mathrm{TE} \mathrm{T3}$ & 241.00 & 255.00 & 65.00 & 2.16 & 0.0309 \\
\hline
\end{tabular}

$\mathrm{VO}_{2} \mathrm{max}$ - maximal oxygen consumption during the arm ergometer test

TE T3 - training exercises performed on a Campus board

Table 4. Sample size of the highest graded OS (OSmax) and RP (RPmax) climbs achieved by the participants abroad or in Poland

\begin{tabular}{lrrrrrrrrr}
\hline OSmax & $\begin{array}{c}\text { Sample } \\
\text { size }\end{array}$ & Cumulative & Percent & Cumulative & RPmax & $\begin{array}{c}\text { Sample } \\
\text { size }\end{array}$ & Cumulative & Percent & Cumulative \\
\hline Poland & 6 & 6 & 19.35 & 19.35 & Poland & 25 & 25 & 80.65 & 80.65 \\
Abroad & 25 & 31 & 80.65 & 100.00 & Abroad & 6 & 31 & 19.35 & 100.00 \\
Missing & 0 & 31 & 0.00 & 100.00 & Missing & 0 & 31 & 0.00 & 100.00 \\
\hline
\end{tabular}

level of difficulty between on-sight and redpoint climbs. Therefore, an estimate index was introduced (RP-OS index), treating the grade of an RP climb as one grade higher on the UIAA scale than $\mathrm{OS}^{4}$ climbs (e.g., X RP and IX OS) [20], which, in simplified terms, a value below " 1 " would indicate a climber who prefers to climb "without knowledge" (i.e., OS) and above "1" signifies their preference for climbing "with knowledge" (i.e., RP). This allowed the climbers to be divided into two groups: RP climbers ( $n=12$, RP-OS index: $1.05-1.55)$ and OS climbers ( $n=19$, RP-OS index: 0.00-0.95). When comparing all of the analyzed characteristics and types of training exercises they perform, the Mann-Whitney $U$ test detected only two variables differentiating the groups: aerobic capacity measured during the arm ergometer test and the frequency of training on the Campus board (Tab. 3). More specifically, $\mathrm{VO}_{2}$ max was higher and more varied in the group of OS climbers while RP climbers practiced more often on a Campus board (Fig. 5).

Besides the above factors, an additional aspect contributing to preference for OS or RP style climbing could also be environmental, specifically, where the participants climb the most often (in Poland or abroad). Therefore, additional analysis was performed by taking this factor into consideration on the best OS and RP climbing results (Tab. 4) with the use of the Chi-squared test, which found statistically significant differences between the two groups $(23.39 ; d f=1 ; p<0.001)$. The highest graded OS climbs were performed abroad, whereas the highest graded RP climbs were achieved in Poland.

${ }^{4}$ The above criteria were confirmed by the results of the 50-best Polish climbers as registered on the website 8a.nu (as of 15/10/2012). These results showed that the mean OS score in this sample was $9.15 \pm 0.5$ (ca. $7 \mathrm{c} / \mathrm{c}+$, min: $7 \mathrm{a}+$, max: $8 \mathrm{~b} / \mathrm{b}+$ ) while the average RP score was $10.13 \pm 0.5$ (ca. 8b/b+, min: 7c+, max: 9a). The differences between the most highly graded routes in both styles among the available climbing history had a mean value close to 1 (RP-OS index $=0.98 \pm 0.04$, min: 0, $\max : 2.2$ ).

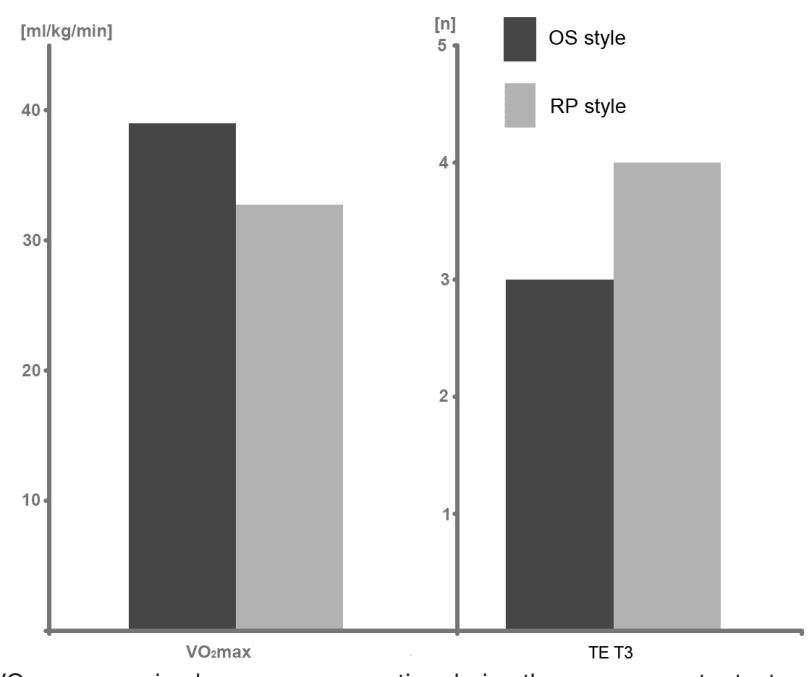

$\mathrm{VO}_{2} \mathrm{max}$ - maximal oxygen consumption during the arm ergometer test, TE T3 - training exercises performed on a Campus board; statistically significant differences between groups at $p<0.05$

Figure 5. Maximal oxygen consumption during the arm ergometer test and frequency of using Campus board training exercises according to climbing style preference (OS vs. RP)

Climbing route preferences

(crux or endurance climbing)

This study also took into account two types of climbing routes popular in outdoor rock climbing: those that are performed at a high intensity but with relatively little effort (crux routes) and those where effort plays a much larger role (endurance routes). To study this aspect, the Mann-Whitney $U$ test was again used to detect any differentiation between climbers' preferences for either of these routes (calculating a Crux-Endurance index in terms of their physical fitness, body build, and the types of exercises performed) (Tab. 5). Those participants $(n=19)$ that preferred endurance routes had on average better fitness results for Type I and Type II flexor finger muscle endurance (FFMmax $50 \%$ and FFMmax70\%, respectively) and higher percent muscle mass (MM\%) (Fig. 6). 
A. Magiera, R. Roczniok, The climbing preferences of advanced rock climbers

Table 5. Results of the Mann-Whitney $U$ test for both groups in terms of the Crux-Endurance index

\begin{tabular}{|c|c|c|c|c|c|}
\hline Variable & $\begin{array}{l}\text { Rank sum } \\
\text { (Crux) }\end{array}$ & $\begin{array}{l}\text { Rank sum } \\
\text { (Endurance) }\end{array}$ & $U$ & Corrected & $p$ level \\
\hline MM\% & 140.50 & 355.50 & 62.50 & $-2.09 *$ & 0.0366 \\
\hline FFMmax $50 \%$ & 134.00 & 362.00 & 56.00 & $-2.35^{*}$ & 0.0186 \\
\hline FFMmax70\% & 143.00 & 353.00 & 65.00 & $-1.99 *$ & 0.0466 \\
\hline OSmax & 145.50 & 350.50 & 67.50 & -1.90 & 0.0578 \\
\hline SMSmax & 147.00 & 349.00 & 69.00 & -1.83 & 0.0680 \\
\hline TE G8 & 147.50 & 348.50 & 69.50 & -1.94 & 0.0526 \\
\hline TE G6 & 149.50 & 346.50 & 71.50 & -1.77 & 0.0765 \\
\hline
\end{tabular}

* denotes statistically significant characteristics at $p<0.05$; MM\% - percent muscle mass, FFMmax $50 \%$ - endurance of Type I flexor finger muscles, FFMmax70\% - endurance of Type II flexor finger muscles, OSmax - highest graded OS climb, SMSmax - shoulder muscle strength, TE G8 - training performed in other sports, TE G6 - training performed by running

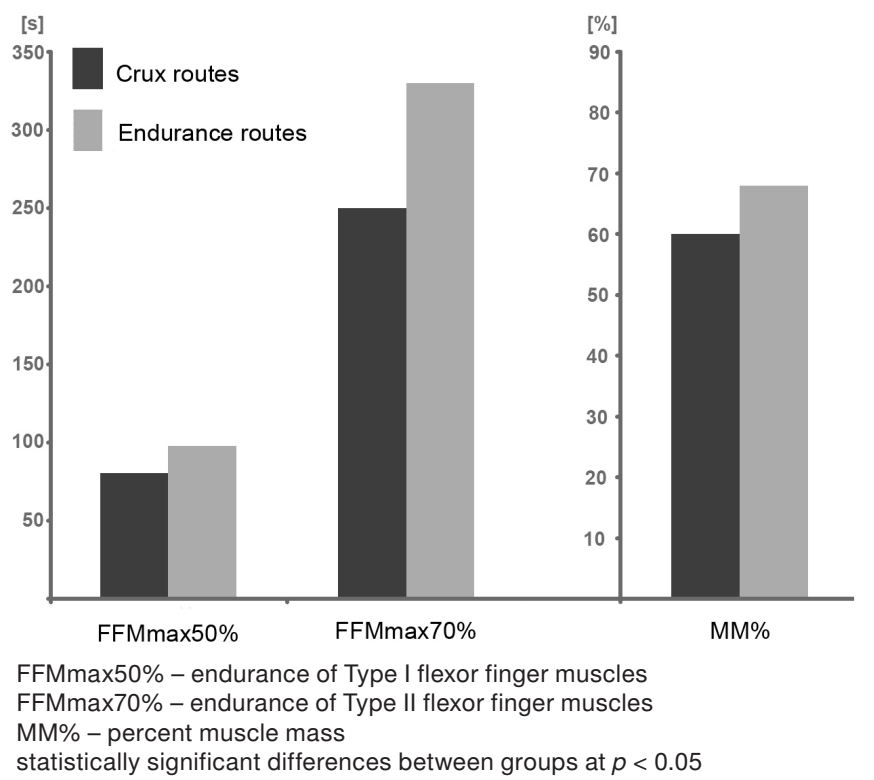

Figure 6. Endurance of Type I and Type II flexor finger muscles and percent muscle mass of the climbers according to their preference for crux or endurance routes

\section{Discussion}

Characteristics of the climbers

Currently, the world record for an on-sight climb is 9 a, while for redpointing $9 \mathrm{~b}+$. Although the climbers who participated in the present study were of a lower performance level (on-sight $-8 \mathrm{a}$, redpoint $-8 \mathrm{~b}+/ \mathrm{c}$ ) than world renowned climbers, their mean results classify them as expert rock climbers based on the criteria adopted by other studies [10,20-22]. Additionally, the mean number of years of experience $(8.32 \pm 3.43$ years $)$ points to their long-term commitment to rock climbing.

In regards to the climber's anthropometric characteristics, the mean values of body height $(177.9 \pm 5.59 \mathrm{~cm})$ and mass $(68.85 \pm 5.02 \mathrm{~kg})$ were slightly higher than what was found in the literature on the subject (about $175 \mathrm{~cm}$ and $66 \mathrm{~kg}$ ) [6, 23]. Nonetheless, the participants' Body Mass Index $\left(21.82 \pm 8.3 \mathrm{~kg} / \mathrm{m}^{2}\right)$, indicating they have average body size, was similar to what was previously reported $\left(20 \mathrm{~kg} / \mathrm{m}^{2}\right)$. However, a difference was noted in percent body fat $(10.42 \pm 3.28 \%)$, which was higher in this group than among other rock climbers $(5.76 \%)$ [23]. This may have been the result of different methods used to measure body composition, as this study used bioelectrical impedance while the previously mentioned studies measured skinfold thickness. These values nonetheless find rock climbers with optimal levels of body fat as well as being much lower than that of the general population (15-18\%). Furthermore, the participants' Ape Index, based on the ratio of arm length to body height, was similar to that recorded by Mermier et al. $(1.0 \pm 0.02)$ [13].

The mean results for the range of movement of the lower limbs at the hips indicated that the participants' flexion was within excepted norms (ca. $\left.120^{\circ}\right)$ for individuals in the same age group (18-40 years), for abduction the range of movement was significantly greater at $51.3 \pm 6.95^{\circ}$ when compared with the norm of $40^{\circ}$ [16]. Flexibility when holding the body close to the wall in the "frog" position showed the greatest differentiation among the participants.

Measures of strength and endurance in rock climbers still lack standardized research tools, although there is a trend to move away from dynamometric measurements in favor of more climbing-specific measuring devices. However, many studies have confirmed that the relative strength of the finger muscles to be an important factor in climbing $[12,23]$. These studies found that climbers registered forces of $0.65-0.96 \mathrm{~N} / \mathrm{kg}$ during dynamometric measurement performed with all four fingers and the thumb $[4,23]$. The lower values of finger strength found among the present group of climbers $(0.56 \mathrm{~N} / \mathrm{kg} \pm 0.06)$ may have been the result of testing grip without the thumb, as this grip is more commonly used in climbing. The simple test on shoulder muscle strength by performing a pull-up with maximum load (SMSmax $=1.64 \pm 0.12$ ) found the results to be in line with Rokowski and Tokarz $(1.7 \pm 0.1 \mathrm{~kg} / \mathrm{kg})$ [12]. Both of these results are significantly higher than those obtained by climbing beginners $(1.3 \pm 0.1 \mathrm{~kg} / \mathrm{kg})$ [21] 
However, comparing the results of the other muscle endurance tests in climbing is a more complicated matter as numerous factors need to be taken into consideration, including: the measurement method, percent maximum voluntary contraction, whether the movement was an isometric or dynamic contraction, whether it was performed continuously or intermittently, and also the loading and unloading times used in an intermittent test. More surprising is the fact that previous studies have not explicitly shown the importance of flexor finger muscle endurance in climbing, although it is known that climbers are able to maintain grip longer than a control group in an intermittent test [23]. In the case of the shoulder's static muscular endurance, the participants in the present study obtained significantly higher results than those by Mermier et al. (SSME $67.19 \pm 13.63 \mathrm{~s}$ vs. $51.80 \pm 14.62 \mathrm{~s}$, respectively) [13]. The reason for such a discrepancy may have been the variation in climbing level of the participants in Mermier et al.'s study, indicated by the range of minimum/maximum values recorded during the shoulder test (19-90 s in Mermier vs. $44-90 \mathrm{~s}$ in this study).

The last morpho-functional characteristic that was considered in the present study was the climbers' aerobic capacity, where maximal oxygen capacity and oxygen uptake at the anaerobic threshold were measured by an arm ergometer test. The involvement of such a smaller muscle group, even in a test performed until exhaustion, could have impacted the results in such a way as to make comparison difficult with climbers who completed other maximal aerobic capacity tests. The participants in the present study obtained $\mathrm{VO}_{2}$ max values of $36.05 \pm 6.76$ $\mathrm{ml} / \mathrm{kg} / \mathrm{min}$, whereas climbers performing on a cycle ergometer using the legs obtained $\mathrm{VO}_{2}$ max values of $45.50 \mathrm{ml} / \mathrm{kg} / \mathrm{min}$. Climbers tested on a climbing ergometer (treadwall) obtained values of $31-51.9 \mathrm{ml} / \mathrm{kg} / \mathrm{min}$ $[23,24]$. Only the results obtained by Bertuzzi et al. [25] on a group of advanced climbers, with $\mathrm{VO}_{2}$ max values of $36.5 \pm 6.2 \mathrm{ml} / \mathrm{kg} / \mathrm{min}$, were similar to those obtained here. However, the dispute over which metabolic processes (aerobic vs. anaerobic) are more prevalent in climbing have not yet been resolved. Bertuzzi et al. [25] believe that indoor climbing involves both aerobic and anaerobic processes, with oxygen uptake at the anaerobic threshold $\left(\mathrm{VO}_{2} \mathrm{AT}\right)$ considered to be one of the main determinants of climbing success among advanced climbers [12].

\section{The training structure of rock climbers}

No studies on the training structure used by rock climbers were found in the literature on the subject. This study evaluated the quantitative characteristics of the training exercises used during the off-season as well the time spent on training and on outdoor climbs during the climbing season.

It was found that advanced rock climbers almost always start with a warm-up before beginning exercise.
This is important as a correctly performed general warmup, followed by a more specialized one, is an essential step in preparing the body for exercise [15] and also aids in reducing the risk of injuries. In rock climbing, one of the most vulnerable parts of the body at risk for injury are the upper limbs (constituting $75-90 \%$ of all injuries), with many studies having focused on analyzing the causes and ways of preventing this type of injury [26]. The loads acting on the annular ligaments of the fingers are known to be almost three times greater than the force applied when gripping a surface, increasing the risk of ligament tears. Hence, a proper warm-up that involves practicing, for example, 100 climbing moves can properly prepare these ligaments before experiencing maximum loads [27].

The use of training exercises by advanced climbers is logical; additional training can allow a climber to achieve a higher level of sports performance as well as ascend ever more demanding climbs in better time. Taking into account the present results, rock climbers most often use a diverse group of general (warm-up), targeted (ladder and Campus board), as well as specialized (bouldering problems, repeating routes, and leading in the OS, FL, and RP styles) training exercises. Unfortunately, this study did not include questions on training periodization plans (linear, nonlinear, block, etc.), making it difficult to analyze the training structure the participants used in line with the corresponding macrocycle periods suggested when planning a training program.

However, the number of hours spent in training $(10.08 \pm 3.61)$ by the participants can provide some useful context. When comparing these values to those obtained in other studies, it was found that they are lower than those reported by Geus et al. [20] $-13 \pm 4 \mathrm{~h} /$ week - but higher than those found by Mermier et al. [13] $7.2 \pm 5 \mathrm{~h} /$ week. In terms of the number of days spent training, Espana-Romero et al. [22] found that advanced climbers trained $3 \pm 1.1$ days per week.

For the present group of Polish climbers, training outdoors often involved traveling to different rock climbing areas located across the country or even abroad. During the climbing season, the participants reported spending $2.95 \pm 0.99$ days per week outdoor rock climbing. When climbing during the seasons, the participants said they preferred climbing cliffs and ascending bolted routes, although half said they were also involved in bouldering. However, $30 \%$ of the climbers claimed they participated in other subtypes of climbing, including Alpinism and multi-pitch, competitive, traditional, and ice climbing. Additionally, almost half of the analyzed climbers performed an additional form of physical activity besides rock climbing (such as cycling or winter sports), although they reported to spend less time on these activities compared with climbing. This may indicate that climbers are active individuals participating in a wide gamut of climbing subtypes and other sports. 
A. Magiera, R. Roczniok, The climbing preferences of advanced rock climbers

\section{Differences in climbing preferences}

Although previous studies included measures of finger flexor muscle strength by hand dynamometry, as it simulates the pinch hold, this study found that only $45 \%$ of the climbers climbed on rock faces that would require the use of this type of grip. Hence, hand dynamometer may be of limited use in climbing despite its obvious advantages (standard measurements, easy application, etc.). Instead, the most preferred types of rock handholds edges and pockets - require climbers to use other types of climbing grips. The popularity of such rock handholds may be explained by environmental factors. For example, the monadnock at Jura Krakowsko-Częstochowska, one of the centers of rock climbing in Poland, is characterized by a large number of pockets and edges due to the type of weathered limestone that is found there. However, the ability to practice on different rock handholds (e.g., slopers) and with various grips (e.g., jamming) may be necessary only in the proper development of beginner climbers.

Instead, one of the major factors that can increase the difficulty of using various grips can be steeper angled rock faces [8]. Advanced climbers prefer overhanging walls both when training and climbing outdoors. There may be many reasons for this, including the ease at which a climb can be controlled in terms of difficulty/intensity, a lowered risk of injury, it being easier to maintain balance than on a vertical wall, and others. For intermediate climbs, the participants said they preferred vertical walls and climbing roofs. None expressed any preference for slab routes. This may be an important consideration for designers of artificial rock walls trying to meet the demands of advanced climbers.

\section{Climbing preferences in terms \\ of style (on-sight or redpoint)}

Among various sports disciplines, there exist a variety of sensory-motor habits that create a specific continuum where at one end are those habits that are almost permanent and independent of external stimuli and performed in a close environment (single-track habits), and, at the other end, habits that arise depending on stimuli stemming from the external environment (multitrack habits), such as the movement of an opponent, how a ball flies through the air, the type of terrain where the activity is performed, waves, wind, etc. [2]. This division, in part, coincides with the sub-styles that exist in climbing. In one sense, rock climbing performed "without knowledge" is based on multi-track habits, including anticipating and adjusting to the various rock faces one is probably going to encounter on a route. In most cases, the climber has only one chance to attempt a route due to increasing fatigue and time constraints. In contrast to this, climbing "with knowledge" provides one with an unlimited amount of time in attempting various handholds until one is able to combine them into a single entity, or, in others words, completing the route to the top. Repeating a climbing route allows a climber to begin to develop single-track habits, where the movement becomes ever more ingrained, allowing the better use of strength and skills in overcoming greater difficulties. Individual preference in a specific sport can be grounded on an overall distribution of such habits: some may prefer to practice in unchanging conditions, improving their skills until reaching perfection (such as in gymnastics or when redpointing), while others prefer to function in a dynamic environment exposed to numerous external stimuli (e.g., soccer, karate, or on-sight climbing). In rock climbing, while every climber will naturally climb in many different types of styles, they may nonetheless prefer only one style over others, and this can be reflected in the number of routes and highest graded climb they perform in that style. The results of this study suggest that climbers who prefer the OS style more often visit climbing areas located abroad as well as have higher $\mathrm{VO}_{2}$ max levels. On the other hand, climbers who prefer redpointing completed their highest graded climbs in Poland and train more often using a Campus board. This, additionally, may be the result of the type of rock most commonly found in Poland (limestone), which is difficult to scale without any foreknowledge. The nature of the types of routes available in Poland require completing quick grips using small handholds, resulting in a larger load on the fingers than on larger muscle groups or the respiratory system. Lastly, one remaining factor is the role location plays, where a climber would more often visit local rock faces and therefore spend more time practicing RP climbs than other styles.

\section{Climbing route preferences (crux or endurance climbs)}

Previous studies have indicated that similarly graded climbing routes can place different demands on the body. A route may be more "technical", such as slab climbing, or be more "physical", such as an overhanging wall problem. Studies that have compared these types of climbing routes have found similarities in mean oxygen consumption and energy expenditure but differences in cardiovascular response and blood lactate concentration [28]. Geus et al. [20] compared four routes graded at the same level of difficulty but with different gradients and/or differently distributed rock handholds, and concluded that:

- routes with vertically spaced handholds caused the highest heart rate (peak and mean heart rate),

- routes with vertically spaced handholds on an overhanging wall are the most physiologically demanding, and

- traverse climbing is the least physiologically demanding. 
Routes can also be divided into those that require one to perform at near maximal intensity but in a short period of time or those where less effort is required and spread over a larger timespan. In this respect, these form additional preferences that climbers may have in choosing climbing routes. This may be confirmed by the results of the test performed on finger endurance, finding that these values were higher in climbers who prefer endurance routes. On the other hand, the lower values of percent muscle mass in climbers who prefer crux routes can be explained by them being focused on increasing strength by improving core and internal coordination instead of building muscle mass.

It should be noted that only those variables related to body composition, exercise capacity, and type of exercise training were taken into consideration in this study and did not include psychological aspects, which may also play a large role in developing preferences for one type of route over another.

\section{Conclusions}

Becoming an advanced rock climber requires meeting numerous essential criteria in terms of body build, physical fitness, expertise, skill level, and mental preparedness, but it does allow one to modify some of these aspects to suit their own preference for climbing type and style. The climbers analyzed in the present study trained with a wide array of exercises, including specialized exercises such as practicing bouldering problems and circuits, repeating climbs, or leading climbs in different styles. This group also spent on average 10 hours per week training and, during the climbing season, spent approximately three days a week climbing outdoors. A few were involved in other climbing subtypes (most commonly climbing on bolted routes both indoors or outdoors and bouldering) and almost half were more involved in other forms of physical activity. Furthermore, this group of advanced climbers was found to be relatively homogeneous in terms of the type of rock faces and rock handholds they preferred, with most preferring overhanging walls and edges. Differences among climbing preferences were also noted in terms of climbing style and route. The best on-sight climbing results were achieved by those who climbed abroad more frequently as well as presented higher maximal oxygen uptake levels during the arm ergometer test. Greater use of targeted training exercises, such as the Campus board, characterized redpoint climbers, whose highest graded climbs were performed in Poland. Some of the climbers preferred intensive but brief climbs, such as routes with concentrated areas of difficulty, while others preferred climbing routes that demanded lengthy although intermittent or steady effort. Those in the latter category were characterized by a higher percentage of muscle mass and better endurance of the finger flexor muscles.
In needs to be repeated that the present study focused on the behavioral differences of advanced climbers, which may differ in relation to beginner climbers. In addition, one of the limits of this study is that it focused only on Polish climbers, whose preferences are subject to local climbing infrastructure, the specific characteristics of local rock climbing areas, and numerous personality traits, among other aspects. As a result, many of issues subjected to analysis in the present study require additional research and study in order to better match what forms of training are most suitable for climbers with different preferences and predispositions.

\section{References}

1. Nikołajczuk L., System of the consumption. Mechanism of social choice [in Polish]. SGPiS, Warszawa 1979.

2. Czajkowski Z., Teaching the sports technique [in Polish]. COS, Warszawa 2004.

3. Booth J., Marino F., Hill C., Gwinn T., Energy cost of sport climbing in elite performers. Br J Sports Med, 1999, 33 (1), 14-18, doi:10.1136/bjsm.33.1.14.

4. Giles L.V., Rhodes E.C., Taunton J.E., The physiology of rock climbing. Sports Med, 2006, 36 (6), 529-545, doi: 10.2165/00007256-200636060-00006.

5. Mermier C.M., Rodbergs R.A., McMinn S.M., Heyward V.H., Energy expenditure and physiological responses during indoor rock climbing. Br J Sports Med, 1997, 31 (3), 224-228, doi: 10.1136/bjsm.31.3.224.

6. Watts P.B., Physiology of difficult rock climbing. Eur J Appl Physiol, 2004, 91 (4), 361-372, doi: 10.1007/s00421003-1036-7.

7. Watts P.B, Daggett M., Gallagher P., Wilkins B., Metabolic response during sport rock climbing and the effects of active versus passive recovery. Int J Sports Med, 2000, 21 (3), 185-190, doi: 10.1055/s-2000-302.

8. Watts P.B., Drobish K.M., Physiological responses to simulated rock climbing at different angles. Med Sci Sports Exerc, 1998, 30 (7), 1118-1122.

9. Gajewski J., Jarosiewicz B., Post-exercise decrease in handgrip force following a single training session in male and female climbers. Hum Mov, 2008, 9 (2), 121-123, doi: 10.2478/v10038-008-0015-6.

10. Watts P.B., Joubert L.M., Lish A.K., Mast J.D., Wilkins B., Antropometry of young competitive sport rock climbers. Br J Sports Med, 2003, 37 (5), 420-424, doi: 10.1136/ bjsm.37.5.420.

11. Watts P.B., Martin D.T., Durtschi S., Anthropometric profiles of elite male and female competitive sport rock climbers. J Sports Sci, 1993, 11 (2), 113-117, doi: 10.1080/ 02640419308729974 .

12. Magiera A., Ryguła I., Biometric Model and Classification Functions in Sport Climbing. J Hum Kinetics, 2007, 18, 87-98.

13. Mermier C.M., Janot J.M., Parker D.L., Swan J.G., Physiological and anthropometric determinants of sport climbing performance. Br J Sports Med, 2000, 34 (5), 359-366, doi: 10.1136/bjsm.34.5.359.

14. Köstermeyer G., Determination, importance and training local muscular endurance of the finger flexors in sport climbing [in German]. Ars Ulna, Neuried 2000.

15. Sozański H (ed.), Basis of the theory of the sports training [in Polish]. COS, Warszawa 1999. 


\section{HUMAN MOVEMENT}

A. Magiera, R. Roczniok, The climbing preferences of advanced rock climbers

16. Drozdowski Z., Sport anthropology [in Polish]. AWF, Poznań 1979.

17. Grant S., Hynes V., Whittaker A., Aitchison T., Anthropometric, strength, endurance and flexibility characteristics of elite and recreational climbers. J Sport Sci, 1996, 14 (4), 301-309, doi: 10.1080/02640419608727715.

18. Müller E., Held Ch., Training the sport climbing specific strength endurance of the finger flexors [in German]. Leistungssport, 1992, 5, 45-49.

19. Hurni M., Coaching climbing: a complete program for coaching young climbing for high performance and safety. Falcon, Guilford 2003.

20. de Geus B., O`Driscoll S.V., Meeusen R., Influence of climbing style on physiological responses during indoor rock climbing on routes with the same difficulty. Eur J Appl Physiol, 2006, 98 (5), 489-496, doi: 10.1007/s00421006-0287-5.

21. Rokowski R., Tokarz R., Importance of motoric capabilities of energy ground in sport climbing in competition of on-sight [in Polish]. Antropomotoryka, 2007, 17 (40), 81-91.

22. Espana-Romero V., Ortega Porcel F.B, Artero E.G., Jimenez-Pavon D., Gutierrez Sainz A., Castillo Garzon M.J. et al., Climbing time to exhaustion is a determinant of climbing performance in high-level sport climbers. Eur J Appl Physiol, 2009, 107 (5), 517-525, doi: 10.1007/s00421009-1155-x.

23. Magiera A., Anthropometry, fitness, anaerobic and aerobic power of rock climbers [in Polish]. In: Mynarski W. (ed.) The theoretical and empirical aspects of recreation and tourism. AWF, Katowice 2008, 282-305.
24. MacLeod D., Sutherland D.L., Buntin L., Whitaker A., Aitchison T., Watt I. et al., Physiological determinants of climbing-specific finger endurance and sport rock climbing performance. J Sport Sci, 2007, 25 (12), 1433-144, doi: $10.1080 / 02640410600944550$.

25. de Moraes Bertuzzi R.C., Franchini E., Kokubun E., Kiss M.A.P.D.M., Energy system contributions in indoor rock climbing. Eur J Appl Physiol, 2007, 101 (3), 293-300, doi: 10.1007/s00421-007-0501-0.

26. Wright D.M., Royle T.J., Marshall T., Indoor rock climbing: who gets injured? Br J Sports Med, 2001, 35 (3), 181-185, doi: 10.1136/bjsm.35.3.181.

27. Schweizer A., Biomechanical properties of the crimp grip position in rock climbers. J Biomech, 2001, 34 (2), 217-223, doi:10.1016/S0021-9290(00)00184-6.

28. Doran D.A., Moncrieff J., Energy expenditure and metabolic cost during technically similar but physically different rock climbing task. J Sport Sci, 1999, 17 (7), 571-609.

Paper received by the Editors: April 11, 2012

Paper accepted for publication: July 11, 2013

Correspondence address

Artur Magiera

Akademia Wychowania Fizycznego

im. Jerzego Kukuczki

ul. Mikołowska 72A

40-065 Katowice, Poland

e-mail: a.magiera@awf.katowice.pl 